\title{
Pengaruh Motivasi Intrinsik dan Motivasi Ekstrinsik terhadap Kinerja Aparatur Sipil Negara (ASN) pada Badan Kesatuan Bangsa dan Politik Kabupaten Kutai Timur
}

\author{
Rizky Aulia Hidayah Syafranuddin \\ Sekolah Tinggi Ilmu Ekonomi Nusantara Sangatta \\ Efendi Rahmanto \\ Sekolah Tinggi Ilmu Ekonomi Nusantara Sangatta \\ rizkyaulia19@gmail.com \\ efendi_rahmanto19@yahoo.com
}

\begin{abstract}
Abstrak
Tujuan dari penelitian ini adalah untuk mengetahui pengaruh motivasi intrinsik dan motivasi ekstrinsik baik secara simultan maupun parsial terhadap kinerja aparatur sipil negara (ASN) pada Badan Kesatuan Bangsa dan Politik Kabupaten Kutai Timur. Sampel dalam penelitian ini adalah seluruh ASN pada Badan Kesatuan Bangsa dan Politik Kabupaten Kutai Timur yang berjumlah 32 orang. Uji yang dilakukan dalam penelitian ini mengunakan uji validitas, reliabilitas, asumsi klasik, regresi berganda, uji $\mathrm{T}$ dan uji $\mathrm{F}$ dengan menggunakan bantuan aplikasi software SPSS 25.0. Hasil penelitian menunjukkan bahwa motivasi intrinsik dan motivasi ekstrinsik baik secara simultan dan parsial berpengaruh positif dan signifikan terhadap kinerja ASN pada Badan Kesatuan Bangsa dan Politik Kabupaten Kutai Timur, atau dapat dikatakan bahwa seluruh hipotesis dalam penelitian ini diterima.
\end{abstract}

\section{Kata Kunci: Motivasi Intrinsik, Motivasi Ekstrinsik, Kinerja}

\section{Pendahuluan}

Sumber daya manusia (SDM) yang berkualitas, profesional serta integritas tinggi dibutuhkan dalam sebuah organisasi sehingga dapat memberikan pelayanan yang baik terhadap masyarakat. Dalam (Republik Indonesia, 2014) Pasal 11 Undang-Undang Republik Indonesia Nomor 5 Tahun 2014 menyebutkan bahwa tugas aparatur sipil negara (ASN) adalah memberikan pelayanan publik yang profesional dan berkualitas. Sehingga dapat dikatakan bahwa peran dari seorang ASN adalah sebagai pelayan bagi masyarakat. Dalam manajemen ASN adalah pengelolaan ASN untuk menghasilkan pegawai ASN yang profesional, memiliki nilai dasar, etika profesi, bebas dari intervensi politik, bersih dari praktik korupsi, kolusi dan nepotisme.

Minimnya kesadaran beberapa karyawan untuk berprestasi atau melakukan kegiatan pengembangan diri karena disebabkan oleh faktor keluarga. Jika setiap ASN memiliki motivasi dari dalam diri (motivasi intrinsik) maka tidak perlu adanya perintah dari atasan untuk melakukan pengembangan diri. Seseorang yang termotivasi, maka tidak memerlukan pengawasan yang ketat dari atasan sebab mereka memiliki inisiatif dan tanggung jawab atas pekerjaan tersebut. Selain motivasi intrinsik sebagai elemen penting dalam bekerja, motivasi ekstrinsik juga diperlukan bagi setiap individu sebagai dorongan dari luar. Sebagai contoh permasalahan yang sering dialami pada Badan Kesatuan Bangsa dan Politik Kab. Kutai Timur adalah pendistribusian gaji dan insentif ASN yang sering mengalami keterlambatan (tidak tepat waktu). 


\section{Rizky Aulia Hidayah Syafranuddin, Efendi Rahmanto}

Selain itu, masih rendahnya kesadaran pegawai untuk mengikuti apel pagi yang rutin dilaksanakan mulai dari hari Senin hingga hari Kamis. Apel pagi merupakan kegiatan wajib yang dilakukan oleh ASN maupun tenaga honorer sebagai bagian dari disiplin kerja. Semakin tinggi motivasi yang dimiliki oleh seseorang maka semakin tinggi pula seseorang untuk meningkatkan kinerjanya. Sedangkan, jika seseorang memiliki motivasi yang rendah dalam bekerja maka rendah pula keinginan seseorang tersebut untuk meningkatkan kinerjanya. Seseorang yang termotivasi akan bekerja berdasarkan inisiatifnya sendiri dan merasa bertanggung jawab atas setiap pekerjaan yang dilakukannya. Sehingga untuk mengatasi permasalahan-permasalahan diatas maka sebuah organisasi dapat mengubah manajemen secara sistematis.

Oleh karena itu, penelitian ini bertujuan untuk mengetahui pengaruh motivasi intrinsik dan motivasi ekstrinsik terhadap kinerja ASN pada Badan Kesatuan Bangsa dan Politik Kabupaten Kutai Timur.

\section{Landasan Teori dan Pengembangan Hipotesis}

\section{Motivasi}

Robbins dalam (Wibowo, 2016) menyebutkan bahwa motivasi sebagai proses yang menyebabkan intensitas (intensity), arah (direction) dan usaha terus menerus (persistence) individu menuju pencapaian tujuan. Menurut (Jaenudin \& Frida,2015), motivasi kerja yaitu keinginan sikap dan perilaku pegawai dalam bekerja atas dorongan dan dukungan yang datang dari dalam dan dari luar diri pegawai untuk mencapainya. Menurut (Huda, 2017) motivasi sering digunakan dalam meningkatkan kinerja suatu organisasi karenanya istilah motivasi seringkali disebut dengan motivasi kerja yang diartikan sebagai dorongan dalam diri individu untuk melakukan sesuatu sesuai tugas dan fungsinya secara lebih baik dan efisien dalam menyelesaikan masalah dalam rangka mencapai tujuan yang telah ditetapkan oleh organisasi.

Sehingga orang diharapkan mampu memiliki motivasi kerja berupa faktor dalam yaitu tanggung jawab pribadi, intensitas (ketekunan) dalam bekerja, kekuatan atau energi dari dalam diri, sedangkan faktor luar yaitu umpan balik atas kinerja dan pencapaian tujuan. Berdasarkan pengertian motivasi menurut para ahli diatas maka dapat disimpulkan bahwa motivasi merupakan dorongan atau rangsangan terhadap perilaku seseorang yang bersumber dari dalam diri atau luar diri seseorang untuk bekerja secara efisien dan profesional demi tercapainya visi atau tujuan dari organisasi tersebut.

Nawawi dalam (Triadi, Hidayah, \& Fasochah, 2019) menjelaskan bahwa motivasi intrinsik adalah pendorong kerja yang bersumber dari dalam diri pekerja sebagai individu berupa kesadaran mengenai pentingnya atau manfaat atau makna pekerjaan yang dilaksanakannya. Sedangkan berdasarkan teori Herzberg menurut Nawawi dalam (Triadi, Hidayah, \& Fasochah, 2019) menyebutkan bahwa motivasi ekstrinsik merupakan motivasi yang menyebabkan orang berpartisipasi secara maksimal karena adanya perangsang dari luar.

Menurut teori Herzberg dalam (Pramono, 2007) mengatakan bahwa faktor-faktor intrinsik dari kerja digolongkan seperti prestasi (achievement), penghargaan, tanggung jawab, bentuk pekerjaan itu sendiri dan pertumbuhan adalah faktor-faktor yang akan lebih banyak mempengaruhi kepuasan kerja dan menyebutnya sebagai faktor pemuas (motivator). Kemudian, faktor-faktor ekstrinsik dari penugasan (job) yaitu kebijakan administrasi, supervisi, hubungan interpersonal, penggajian (salary), status dan keamanan kerja akan lebih berpengaruh pada ketidakpuasan kerja atau dikenal dengan sebutan faktor higine. 
Semakin tinggi motivasi yang dimiliki oleh seseorang maka semakin tinggi pula keinginan seseorang tersebut untuk bekerja secara profesional, bertanggung jawab serta berupaya untuk berprestasi sehingga meningkatkan kinerja. Jika seseorang tidak memiliki motivasi untuk bekerja dengan baik maka rendah pula kinerja yang akan dihasilkan sehingga tujuan yang ingin dicapai tidak akan tercapai.

\section{Kinerja}

(Wirawan, 2015) menyebutkan bahwa performance atau kinerja adalah keluaran yang dihasilkan oleh fungsi-fungsi atau indikator-indikator suatu pekerjaan atau suatu profesi dalam waktu tertentu. Kinerja merupakan suatu proses tentang bagaimana pekerjaan berlangsung untuk mencapai hasil kerja, maka dari hasil pekerjaan tersebut dapat menunjukkan kinerja (Wibowo, 2016). Menurut Armstrong dan Baron dalam (Wibowo, 2016), faktor-faktor yang mempengaruhi kinerja adalah personal factors, leadership factor, team factors, system factors dan contextual/situational factors. Menurut Mangkunegara dalam (Tanuwibowo \& Setiawan, 2015) indikator kinerja yaitu kualitas, kuantitas, pelaksanaan tugas dan tanggung jawab.

Berdasarkan pendapat dari para ahli bahwa kinerja adalah output yang dihasilkan oleh individu atau kelompok yang telah menjalankan suatu pekerjaan dimana pekerjaan tersebut mencapai target atau tujuan. Kinerja yang baik dihasilkan dari seseorang yang memiliki motivasi tinggi dalam dirinya dan merasa bertanggung jawab atas pekerjaan tersebut. Sebaliknya, kinerja seseorang akan rendah apabila seseorang tersebut tidak memiliki motivasi yang timbul dari dalam dirinya.

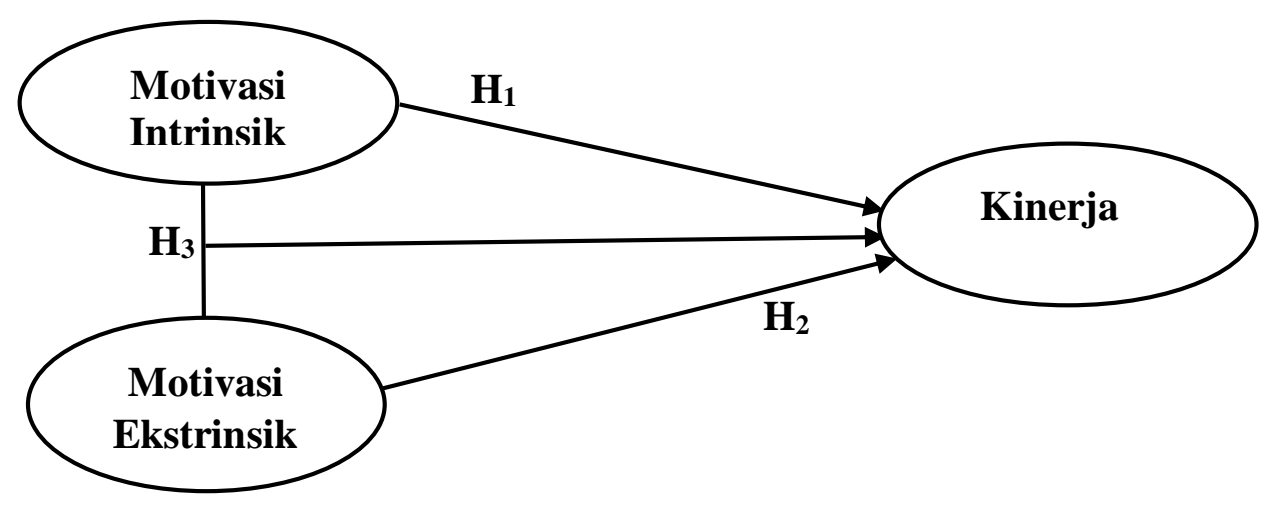

Gambar 1 Kerangka Pikir

Sumber : Herzberg dalam (Pramono, 2007) dan Mangkunegara dalam (Tanuwibowo \& Setiawan, 2015)

\section{Hipotesis}

1. Diduga motivasi intrinsik berpengaruh terhadap kinerja aparatur sipil negara (ASN) pada Badan Kesatuan Bangsa dan Politik Kabupaten Kutai Timur.

2. Diduga motivasi ekstrinsik berpengaruh terhadap kinerja aparatur sipil negara (ASN) pada Badan Kesatuan Bangsa dan Politik Kabupaten Kutai Timur.

3. Diduga motivasi intrinsik dan motivasi ekstrinsik secara simultan berpengaruh terhadap kinerja aparatur sipil negara (ASN) pada Badan Kesatuan Bangsa dan Politik Kabupaten Kutai Timur. 


\section{Metode Penelitian}

(Sugiyono, 2018) menyatakan populasi adalah wilayah generalisasi yang terdiri atas : obyek/subyek yang mempunyai kuantitas dan karakteristik tertentu yang ditetapkan oleh peneliti untuk dipelajari dan kemudai ditarik kesimpulannya. Populasi dalam penelitian ini adalah aparatur sipil negara (ASN) pada Kantor Badan Kesatuan Bangsa dan Politik Kabupaten Kutai Timur yang berjumlah 32 orang. Semua populasi dijadikan sampel. Metode yang digunakan dalam penelitian ini adalah metode kuantitatif dan analisis dibantu menggunakan aplikasi software SPSS 25.0.

\section{Pembahasan}

Uji validitas daftar pertanyaan untuk mengukur valid atau tidaknya kuesioner. Suatu kuesioner dikatakan valid apabila pertanyaan pada kuesioner mampu mengukur apa yang hendak diukur dengan menggunakan metode corrected item - total correlation yaitu dilakukan dengan cara mengkorelasikan masing-masing score item dengan skor total dan melakukan korelasi terhadap nilai koefisien korelasi yang over estimate. Hal ini dilakukan agar tidak terjadi koefisien item total yang over estimate. Dengan demikian, maka dapat disajikan hasil uji validitas atas motivasi intrinsik dan motivasi ekstrinsik aparatur sipil negara (ASN) pada Badan Kesatuan Bangsa dan Politik Kabupaten Kutai Timur menggunakan SPSS 25.0 yang dapat dilihat pada tabel sebagai berikut:

Tabel 1 Hasil Uji Validitas Motivasi Intrinsik

\begin{tabular}{|c|c|c|}
\hline No & Nilai Validitas & Keterangan \\
\hline 1 &, $729^{* *}$ & Valid \\
\hline 2 &, $634^{* *}$ & Valid \\
\hline 3 &, $840^{* *}$ & Valid \\
\hline 4 &, $487^{* *}$ & Valid \\
\hline 5 &, $791^{* *}$ & Valid \\
\hline
\end{tabular}

Sumber : Data Primer yang Diolah (2019)

Berdasarkan hasil uji validitas variabel motivasi intrinsik pada tabel 1 ditemukan nilai koefisien korelasi 0,487 - 0,791 dinyatakan valid, sehingga dapat disimpulkan bahwa kelima item pertanyaan valid karena memiliki nilai corrected item total correlation di atas 0,3494 dan layak untuk digunakan penelitian.

Tabel 2 Hasil Uji Validitas Motivasi Ekstrinsik

\begin{tabular}{|c|c|c|}
\hline No & Nilai Validitas & Keterangan \\
\hline 1 &, $659^{* *}$ & Valid \\
\hline 2 &, $617^{* *}$ & Valid \\
\hline 3 &, $790^{* *}$ & Valid \\
\hline 4 &, $520^{* *}$ & Valid \\
\hline 5 &, $617^{* *}$ & Valid \\
\hline 6 &, $790^{* *}$ & Valid \\
\hline
\end{tabular}

Sumber : Data Primer yang Diolah (2019) 
Berdasarkan hasil uji validitas variabel motivasi ekstrinsik pada tabel 2 ditemukan nilai koefisien korelasi 0,520 - 0,790 dinyatakan valid, sehingga dapat disimpulkan bahwa keenam item pertanyaan valid karena memiliki nilai corrected item total correlation diatas 0,3494 dan layak untuk digunakan penelitian.

Tabel 3 Hasil Uji Validitas Kinerja

\begin{tabular}{|c|c|c|}
\hline No & Nilai Validitas & Keterangan \\
\hline 1 &, $702^{* *}$ & Valid \\
\hline 2 &, $799^{* *}$ & Valid \\
\hline 3 &, $392^{*}$ & Valid \\
\hline 4 &, $741^{* *}$ & Valid \\
\hline
\end{tabular}

Sumber : Data Primer yang Diolah (2019)

Berdasarkan hasil uji validitas variabel kinerja pada tabel 3 ditemukan nilai koefisien korelasi 0,392 - 0,799 dinyatakan valid, sehingga dapat disimpulkan bahwa keempat item pertanyaan valid karena memiliki nilai corrected item total correlation di atas 0,3494 dan layak untuk digunakan penelitian.

Tabel 4 Hasil Uji Reliabilitas

\begin{tabular}{|c|c|c|c|}
\hline No & Kode Pertanyaan & Cronbach's Alpha & Keterangan \\
\hline 1 & Motivasi Intrinsik & 0,724 & Reliabel \\
\hline 2 & Motivasi Ekstrinsik & 0,756 & Reliabel \\
\hline 3 & Kinerja & 0,683 & Reliabel \\
\hline
\end{tabular}

Sumber : Data Primer yang Diolah (2019)

Dari tabel 4 diatas yaitu hasil uji reabilitas atas variabel motivasi intrinsik, motivasi ekstrinsik dan kinerja, semua item menunjukkan reliabel sebab memiliki nilai cronbach's alpha $(\alpha)$ diatas 0,60. Dimana untuk variabel motivasi intrinsik cronbach's alpha sebesar 0,724, motivasi ekstrinsik dengan cronbach's alpha sebesar 0,756, dan kinerja cronbach's alpha sebesar 0,683, sehingga dapat dikatakan bahwa semua variabel tersebut reliabel karena memiliki nilai $r$ standar di atas dari 0,60 .

Tabel 5 Koefisian Korelasi dan Koefisian Determinasi

\begin{tabular}{|c|c|c|c|c|c|}
\hline Model & R & R Square & $\begin{array}{c}\text { Adjusted } R \\
\text { Square }\end{array}$ & $\begin{array}{c}\text { Std. Error of the } \\
\text { Estimate }\end{array}$ & $\begin{array}{c}\text { Durbin- } \\
\text { Watson }\end{array}$ \\
\hline 1 &, $741^{\mathrm{a}}$ &, 549 &, 518 & 1,37755 & 1,823 \\
\hline
\end{tabular}

Sumber : Data Primer yang Diolah (2019)

Berdasarkan hasil dapat didapat nilai koefisien korelasi (R) sebesar 0,741 atau 74,1\% nilai tersebut termaksud termasuk dalam hubungan yang " kuat " karena berada pada interval korerasi diatas $0,61-0,80$. Hal ini berarti terdapat hubungan kuat antara variabel motivasi intrinsik dan motivasi ekstrinsik terhadap kinerja. Selanjutnya koefisien determinasi $\left(\mathrm{R}^{2}\right)$ sebesar 0,549 artinya bahwa 54,9\% variasi oleh variabel kinerja dapat dijelaskan oleh variabel motivasi intrinsik dan motivasi ekstrinsik sedangkan sisanya sebesar 45,1\% dijelaskan oleh variabel lain yang tidak termasuk dalam penelitian ini. 
INOBIS: Jurnal Inovasi Bisnis dan Manajemen Indonesia Volume 02, Nomor 03, Bulan Juni 2019

Rizky Aulia Hidayah Syafranuddin, Efendi Rahmanto

Tabel 6 Uji Regresi Berganda dan Uji Hipotesis

\begin{tabular}{|c|c|c|c|c|c|c|c|}
\hline \multirow{2}{*}{ Model } & \multicolumn{2}{|c|}{$\begin{array}{c}\text { Unstandardized } \\
\text { Coefficients }\end{array}$} & \multirow{2}{*}{$\begin{array}{c}\begin{array}{c}\text { Standardized } \\
\text { Coefficients }\end{array} \\
\text { Beta }\end{array}$} & \multirow{2}{*}{$\mathbf{t}$} & \multirow{2}{*}{ Sig. } & \multicolumn{2}{|c|}{$\begin{array}{c}\text { Collinearity } \\
\text { Statistics }\end{array}$} \\
\hline & B & Std. Error & & & & $\begin{array}{c}\text { Toleranc } \\
e\end{array}$ & VIF \\
\hline 1 (Constant) & 1,117 & 2,249 & &, 460 & .696 & & \\
\hline Intrinsik &, 319 & , 127 & ,374 & $\begin{array}{r}2,51 \\
0\end{array}$ & .018 & ,699 & 1,430 \\
\hline Ekstrinsik &, 342 &, 109 & ,466 & $\begin{array}{r}3,12 \\
6\end{array}$ & .004 & ,699 & 1,430 \\
\hline
\end{tabular}

Sumber : Data Primer yang Diolah (2019)

Berdasarkan tabel 6 yakni hasil olah data regresi dengan menggunakan program SPSS 25.0 maka persamaan regresinya yaitu :

$$
\mathrm{Y}=1,117+0,319 \mathrm{X}_{1}+0,342 \mathrm{X}_{2}
$$

Hasil dari persamaan tersebut mempunyai arti bahwa, konstanta sebesar 1,117 artinya jika motivasi intrinsik $\left(\mathrm{X}_{1}\right)$ dan motivasi ekstrinsik $\left(\mathrm{X}_{2}\right)$ nilainya adalah 0 , maka kinerja pegawai $(Y)$ nilainya adalah 1,117 . koefisien motivasi intrinsik $\left(\mathrm{X}_{1}\right)$ sebesar 0,319 , artinya jika variabel independen lainnya bernilai tetap dan motivasi intrinsik $\left(\mathrm{X}_{1}\right)$ mengalami kenaikan 1 , maka kinerja (Y) akan mengalami kenaikan sebesar 0,319. Koefisien variabel motivasi intrinsik bernilai positif dan nilai probabilitas signifikansi sebesar 0,018 $<0,05$ yang berarti variabel motivasi intrinsik berpengaruh positif dan signifikan terhadap kinerja, dimana semakin naik nilai motivasi intrinsik maka akan semakin meningkat pula kinerja. Koefisien motivasi ekstrinsik $\left(\mathrm{X}_{2}\right)$ sebesar 0,342 , artinya jika variabel independen lainnya bernilai tetap dan motivasi ekstrinsik $\left(\mathrm{X}_{2}\right)$ mengalami kenaikan 1, maka kinerja $(\mathrm{Y})$ akan mengalami kenaikan sebesar 0,342. Koefisien motivasi ekstrinsik bernilai positif dan nilai probabilitas signifikansi sebesar 0,004 < 0,05 yang berarti variabel motivasi ekstrinsik berpengaruh positif dan signifikan terhadap kinerja, dimana semakin naik nilai motivasi ekstrinsik maka akan semakin meningkat pula kinerja.

Dari hasil koefisien regresi maka diperoleh $\mathrm{t}_{\text {hitung }}$ untuk motivasi intrinsik sebesar 2,510 dan $t_{\text {tabel }}$ sebesar 2,042 serta memiliki probabilitas $0,018<0,05$. Karena nilai thitung lebih besar dari $t_{\text {tabel }}$ serta memiliki nilai probabilitas lebih kecil dari nilai standar, maka dapat dikatakan bahwa motivasi intrinsik memiliki pengaruh positif dan signifikan terhadap kinerja. Dari hasil perhitungan di atas berarti hipotesis 1 diterima. Dari hasil koefisien regresi maka diperoleh $t_{\text {hitung }}$ untuk motivasi ekstrinsik sebesar 3,126 dan $t_{\text {tabel }}$ sebesar 2,042 serta memiliki probabilitas $0,004<0,05$. Karena nilai $t_{\text {hitung }}$ lebih besar dari $t_{\text {tabel }}$ serta memiliki nilai probabilitas lebih kecil dari nilai standar, maka dapat dikatakan bahwa motivasi ekstrinsik memiliki pengaruh positif dan signifikan terhadap kinerja. Dari hasil perhitungan di atas berarti hipotesis 2 diterima.

Untuk membuktikan bahwa motivasi intrinsik dan motivasi ekstrinsik memiliki pengaruh yang simultan atau serempak terhadap kinerja maka dapat dilakukan dengan uji $\mathrm{F}$. dalam anova diperoleh nilai $F_{\text {hitung }}(17,637>2,90)$ dan selain itu memiliki nilai probabilitas < alpha $(0,000<0,05)$, maka dapat dikatakan bahwa model regresi dapat digunakan untuk dapat memprediksi kinerja. Hal ini berarti semakin tinggi motivasi intrinsik dan motivasi ekstrinsik maka akan berdampak simultan terhadap kinerja, sebaliknya semakin rendah motivasi intrinsik 
dan motivasi ekstrinsik ASN Badan Kesatuan Bangsa dan Politik Kabupaten Kutai Timur maka akan menyebabkan menurunnya kinerja ASN, sehingga dapat dikatakan bahwa motivasi intrinsik dan motivasi ekstrinsik berpengaruh secara simultan terhadap kinerja. Dari hasil di atas maka berarti hipotesis 3 diterima.

Dari hasil uji regersi berganda dan uji hipotesisi baik uji T dan Uji F menyatakan bahwa motivasi intrinsik dan motivasi ektrinsik berpengaruh positif dan signifikan terhadan kinerja ASN Badan Kesatuan Bangsa dan Politik Kabupaten Kutai Timur, dengan arti lain bahwa untuk miningkatkan atau mempertahankan kinerja maka motivasi intrinsik dan ekstrinsik ASN harus terpenuhi. Dengan baiknya motivasi intrinsik dan ekstrinsik yang diterima oleh ASN akan berdampak langsung pada kinerja ASN tersebut.

\section{Kesimpulan}

Penelitian yang dilakukan di Badan Kesatuan Bangsa dan Politik Kabupaten Kutai Timur dengan tujuan untuk mengetahui pengaruh motivasi intrinsik dan motivasi ekstrinsik terhadap kinerja memiliki kesimpulan yaitu sebagai berikut :

1. Motivasi intrinsik berpengaruh positif dan signifikan terhadap kinerja ASN pada Badan Kesatuan Bangsa dan Politik Kabupaten Kutai Timur.

2. Motivasi ekstrinsik berpengaruh positif dan signifikan terhadap kinerja ASN pada Badan Kesatuan Bangsa dan Politik Kabupaten Kutai Timur.

3. Motivasi intrinsik dan motivasi ekstrinsik secara simultan berpengaruh positif dan signifikan terhadap kinerja ASN pada Badan Kesatuan Bangsa dan Politik Kabupaten Kutai Timur.

\section{Daftar Pustaka}

Huda, S. (2017). Kinerja Pimpinan . Jambi: Pusat Studi Agama dan Kemasyarakatan (PUSAKA).

Jaenudin, \& F. C. (2015). Faktor-Faktor yang Mempengaruhi Kinerja Aparatur Sipil Negara (ASN) pada Sekretariat Daerah Kabupaten Bulungan. Jurnal Administrasi Negara Vol. 21 Nomor 2 Bulan Agustus, 50-61.

Pramono, J. (2007). Pengaruh Faktor Higine dan Pemuas pada Motivasi dan Kinerja : Uji Terhadap Teori Herzberg. Jurnal Optimal Vol. 1 No. 1 Bulan Maret.

Republik Indonesia, L. N. (2014, Januari 15). Undang-Undang Republik Indonesia Nomor 5 Tahun 2014. Retrieved from https://jdih.kemenkeu.go.id/fulltext/2014/5TAHUN2014UU.htm

Sugiyono. (2018). Metode Penelitian Manajemen. Bandung: Penerbit Alfabeta.

Tanuwibowo, M. H., \& Setiawan, R. (2015). Pengaruh Budaya Organisasi dan Motivasi Kerja terhadap Kinerja Karyawan pada PT Lestari Purnama Perkasa. AGORA Vol. 3 Nomor 2 .

Triadi, R., Hidayah, S., \& Fasochah. (2019). Pengaruh Motivasi Intrinsik dan Ekstrinsik terhadap Kinerja Pegawai yang Dimediasi oleh Komitmen Organisasi (Studi pada Pegawai Kantor Pertanahan Kota Semarang). Jurnal Ekonomi Manajemen dan Akuntanis Nomor 47/Th. XXVI/Bulan Oktober.

Wibowo. (2016). Manajemen Kinerja Edisi Kelima. Jakarta: PT Rajagrafindo Persada.

Wirawan. (2015). Evaluasi Kinerja Sumber Daya Manusia (Teori, Aplikasi dan Penelitian). Jakarta: Penerbit Salemba Empat. 